Jullie Anne Chiste*, Isabella Naomi Furuie, Meri Bordignon Nogueira, Jessica da Silva Longo, Cyllian Arias Fugaça, Barbara Maria Cavalli, Carolina Tanaka Dino, Sonia Mara Raboni, Narcizo Leopoldo Eduardo da Cunha Sobieray and Newton Sérgio de Carvalho

\title{
SARS-CoV-2 in asymptomatic pregnant women in South Brazil: RT-PCR and serological detection
}

https://doi.org/10.1515/jpm-2021-0173

Received April 10, 2021; accepted May 26, 2021;

published online June 10, 2021

\section{Abstract}

Objectives: This study aims to detect the SARS-CoV-2 infection prevalence in asymptomatic pregnant women.

Methods: A group of 195 asymptomatic pregnant women who attended the prenatal care outclinic and to the obstetric emergency department was tested concomitantly for SARS-CoV-2 by RT-PCR and serological tests.

Results: The virus was detected by RT-PCR in two (1.02\%) cases and $17(8.71 \%)$ patients had antibodies detected by immunochromatographic tests.

Conclusions: Due to the high risk of this emerging infection in the health of pregnant women, fetuses and newborns, we suggest the universal screening of all pregnant women admitted to hospital through the combined method RT-PCR and serological.

Keywords: asymptomatic COVID-19; COVID-19; pregnancy; RT-PCR; SARS-CoV-2; serological antibodies.

*Corresponding author: Jullie Anne Chiste, Rua Saldanha da Gama, 86, apto 32A, Centro, Zip Code: 80060-170, Curitiba, Brazil; and Department of Obstetrics and Gynecology, Hospital de Clínicas, Universidade Federal do Paraná, Curitiba, Brazil, Phone: +55 41 98870-1481, E-mail: julliext@gmail.com. https://orcid.org/00000001-7875-4126

Isabella Naomi Furuie, Jessica da Silva Longo, Cyllian Arias Fugaça and Narcizo Leopoldo Eduardo da Cunha Sobieray, Department of Obstetrics and Gynecology, Hospital de Clínicas, Universidade Federal do Paraná, Curitiba, Brazil

Meri Bordignon Nogueira, Virology Laboratory, Hospital de Clínicas, Universidade Federal do Paraná, Curitiba, Brazil; and Post Graduate Program in Gynecology and Obstetrics, Federal University of Paraná (UFPR), Curitiba, Brazil

Barbara Maria Cavalli, Carolina Tanaka Dino and Sonia Mara Raboni, Virology Laboratory, Hospital de Clínicas, Universidade Federal do Paraná, Curitiba, Brazil

Newton Sérgio de Carvalho, Department of Obstetrics and Gynecology, Hospital de Clínicas, Universidade Federal do Paraná, Curitiba, Brazil; and Post Graduate Program in Gynecology and Obstetrics, Federal University of Paraná (UFPR), Curitiba, Brazil

\section{Introduction}

The severe acute respiratory syndrome caused by the new SARS-CoV-2 has victimized millions of people worldwide since the first case in China in December 2019. This virus is transmitted mainly via respiratory droplets when near an infected person, although the transmission can occur by asymptomatic carrier. Indeed, a systematic review suggested that the real asymptomatic transmission is uncommon, but the pre-symptomatic transmission as the major reason for its propagation [1].

There are few studies on aspects of viral infection in pregnant women, as well as the risk of vertical transmission, the fetal and neonatal compromises. However, reports have shown that pregnant and puerperal women are more susceptible for complications [2-4]. In this study we assessed the prevalence of SARS-CoV-2 infection in asymptomatic pregnant women.

\section{Materials and methods}

This is a cohort study carried out from September to October 2020, at Complexo Hospital de Clínicas da Universidade Federal do Paraná (CHC-UFPR), a tertiary care academic center in South Brazil. The Institutional Ethical Committee boarding reviewed and approved the study (CAAE: 35129820.6.0000.0096), and Informed Consent Term was signed by all participants. Pregnant women were included, randomly and voluntarily, at any gestational age, who attended the obstetrics emergency sector and the prenatal care out clinic of highrisk pregnancy. The patients were invited to participate in the research after consulting the prenatal appointment or while waiting for emergency care, and, above all, it is important to note that all participants selected from the emergency room had mild gestational complaints and were not in labor. The inclusion criteria were: pregnancy at any gestational age and the absence of COVID-19 symptoms as fever, sore throat, cough, coryza, headache, diarrhea, anosmia and ageusia. The exclusion criteria were the previous diagnosis of COVID-19 and the patient's refusal to participate. It was collected nasopharyngeal and oropharyngeal swabs for RT-PCR for SARS-CoV-2, and a serum specimen for serological tests. Samples were sent to the Virology Laboratory of the CHC-UFPR, which is certified by the health public laboratory of Paraná State, Brazil.

Detection of SARS-CoV-2 in nasopharyngeal and oropharyngeal samples was performed by RT-PCR method targeting ORF 1ab gene and $N$ region gene. Viral RNA isolation was performed by using Biopur 
Viral Nucleic Acid Isolation Kit (Mobius Life Science, Curitiba-Paraná, Brazil) according to the manufacturer's instructions; Real-time reverse-transcription PCR was performed by using KIT BIOMOL OneStep/COVID-19 (Instituto de Biologia Molecular do Paraná - IBMP, Brazil). This assay includes two viral genes $O R F 1 a b$ gene and $N$ region gene SARS-CoV-2 detection according to the manufacturer's instructions, a human endogenous gene was used as target for internal control.

Serological tests were carried out using lateral flow immunochromatographic assays (LFAs), based on colloidal gold-labeled immunochromatography (GICA) principle and one-step method with results obtained within $15 \mathrm{~min}$. The kits detect IgM/IgG antibodies for SARS-CoV-2 (COVID-19 IgG/IgM ECO Test (Ecodiagnóstica, Brazil). The tests were performed at room temperature according to the manufacturer's instructions. The recommended sample volume of $2 \mu \mathrm{L}$ serum was added to the specimen well on the individual test cassettes followed by the addition of the buffer (two drops). The result was read visually after $15 \mathrm{~min}$, by two researchers; in case of doubt a third one checked it.

The performance of four immunochromatographic tests was performed for our group, including the ECO test, used in this study. Our data demonstrate the excellent performance of LFA for the diagnosis of definite or probable SARS-CoV-2 infection Eco test IgG (sensitivity, 95\%; specificity, 99\%; positive predictive value (PPV) 95\%; negative predictive value (NPV) 100\%); IgM (sensitivity, 90\%; specificity, 94\%; PPV 89\%; NPV 94\%) [5].

Those patients with positive test for SARS-CoV-2 were informed to take the measures following the protocol as isolation, symptoms developing, prenatal care attendance and implementation of safety measures during the delivery.

\section{Results and discussion}

A total of 195 asymptomatic pregnant women was included in the study, SARS-CoV-2 infection was detected in two cases through the RT-PCR method, and 17 patients presented IgM and IgG antibodies through serological examination. Of these, 16 had only IgG and one had only IgM reagent. All patients with reagent serology had a negative RT-PCR test. Table 1 includes the demographic data of all patients who presented positive serological test and SARS-CoV-2 RT-PCR. Therefore, the prevalence of anti-

Table 1: Demographic characteristics of asymptomatic pregnant women with laboratory-confirmed SARS-CoV-2 infection.

\begin{tabular}{|c|c|c|c|c|c|c|}
\hline Patient & $\begin{array}{l}\text { Diagnostic } \\
\text { test }\end{array}$ & $\begin{array}{r}\text { Maternal } \\
\text { age, years }\end{array}$ & $\begin{array}{r}\text { Gestational age at } \\
\text { diagnosis, weeks }\end{array}$ & Maternal comorbid conditions & Observations & $\begin{array}{l}\text { Health care } \\
\text { department }\end{array}$ \\
\hline 1 & RT-PCR & 21 & 38 & None & & Antenatal clinic \\
\hline 2 & RT-PCR & 30 & 22 & None & $\begin{array}{l}\text { Dichorionic diamniotic } \\
\text { pregnancy }\end{array}$ & Antenatal clinic \\
\hline 3 & $\lg M$ & 36 & 36.5 & Diabetes Mellitus type II, obesity & & Antenatal clinic \\
\hline 4 & IgG & 37 & 38.6 & Deep Venous Thrombosis & & Antenatal clinic \\
\hline 5 & IgG & 33 & 33.4 & Pre-existing hypertension, obesity & & Emergency care \\
\hline 6 & $\lg G$ & 38 & 39.4 & Depression, previous gastrectomy & & Emergency care \\
\hline 7 & $\lg G$ & 30 & 38.4 & $\begin{array}{l}\text { Gestational diabetes mellitus; } \\
\text { hypothyroidism }\end{array}$ & & Antenatal clinic \\
\hline 8 & $\lg G$ & 29 & 34.3 & Acute toxoplasmosis & & Antenatal clinic \\
\hline 9 & IgG & 37 & 35.1 & Hypothyroidism, smoking & & Antenatal clinic \\
\hline 10 & $\lg G$ & 33 & 38.1 & $\begin{array}{l}\text { Nephrolithiasis, recurrent urinary } \\
\text { tract infection }\end{array}$ & & Antenatal clinic \\
\hline 11 & $\lg G$ & 35 & 14.3 & $\begin{array}{l}\text { Pre-existing hypertension, recur- } \\
\text { rent miscarriages }\end{array}$ & & Antenatal clinic \\
\hline 12 & $\lg G$ & 45 & 37 & $\begin{array}{l}\text { Gestational diabetes mellitus; } \\
\text { gestacional hypertension }\end{array}$ & & Antenatal clinic \\
\hline 13 & IgG & 23 & 12.6 & Pre-existing hypertension & & Antenatal clinic \\
\hline 14 & $\lg G$ & 29 & 8.1 & $\begin{array}{l}\text { Epilepsy, migraine, neph- } \\
\text { rolithiasis, hyperemesis } \\
\text { gravidarum }\end{array}$ & & Antenatal clinic \\
\hline 15 & $\lg G$ & 30 & 39 & & $\begin{array}{l}\text { Fetal pelvicalyceal } \\
\text { dilation }\end{array}$ & Antenatal clinic \\
\hline 16 & IgG & 20 & 23.2 & Asthma & & Antenatal clinic \\
\hline 17 & $\lg G$ & 43 & 20.2 & $\begin{array}{l}\text { Gestational diabetes mellitus, } \\
\text { syphilis }\end{array}$ & & Antenatal clinic \\
\hline 18 & $\operatorname{IgG}$ & 30 & 32.1 & & $\begin{array}{l}\text { Monochorionic dia- } \\
\text { mniotic pregnancy }\end{array}$ & Antenatal clinic \\
\hline 19 & $\lg G$ & 33 & 36.6 & & $\begin{array}{l}\text { Dichorionic diamniotic } \\
\text { pregnancy }\end{array}$ & Antenatal clinic \\
\hline
\end{tabular}


SARS-CoV-2 antibodies in asymptomatic pregnant women found was $8.71 \%$ and the detection of asymptomatic infection, verified by the "gold standard" RT-PCR methodology, was $1.02 \%$.

Of the two cases diagnosed with infection by the RT-PCR method, one patient was at gestational age of 38 weeks and four days, without comorbidities, was admitted at 39 weeks for labor induction for suspected fetal growth restriction with estimated fetal weight in the 7th percentile and abdominal circumference in the 3rd percentile for gestational age with normal amniotic fluid index, which was later discarded. She remained asymptomatic during hospitalization and underwent cesarean section two days later due to induction failure, the neonate was born with 3,350 $\mathrm{g}$ and Apgar score of 9 and 10 reported at 1 and 5 min, respectively. An Italian prospective case control study did not find an association between pregnancies complicated by SARS-CoV-2 infection and a higher risk of developing fetal growth restriction, with no difference in head circumference, abdominal circumference, femur length, estimated fetal weight $z$ scores and pulsatility index of both maternal and fetal Doppler scans, compared to the group of pregnancies not exposed to the virus [6]. The other case was a diamniotic dichorionic twin pregnancy that showed RT-PCR reagent at a gestational age of 22 weeks and one day, when she was asymptomatic and in the following days presented mild respiratory condition, with evolution to vaginal delivery of the first fetus at 32 weeks and four days due to premature labor, being submitted to cesarean section two days later for the birth of the second fetus due to failure of induction, maternal exhaustion and breech presentation fetus.

The prevalence rates of asymptomatic SARS-CoV-2 infected individuals vary widely between studies. The proportion of asymptomatic pregnant women among the total confirmed cases is also variable in the published data: a Chinese study found a proportion of $23.3 \%$ [7], while in New York hospitals it was 32.6\% [8]. A multinational retrospective cohort study included all pregnant women with laboratory-confirmed SARS-CoV-2 infection in 22 different countries and found a rate of $24.2 \%$ asymptomatic women [9]. Some studies conducted the universal search for SARS-CoV-2 by RT-PCR in patients who were hospitalized for termination of pregnancy: a Portuguese study estimated approximately $11 \%$ of asymptomatic pregnant with positive RT-PCR [10]; lower prevalence, of approximately 2.5\%, was observed in two hospitals in Philadelphia [11], and, similarly, 2.9\% in another American study [12].

Most studies on COVID-19 in pregnant women are performed in symptomatic patients, and are usually published as case reports. However, in a national American sample of 91,412 infected women, no difference was observed regarding presence of symptom between pregnant and non-pregnant, 97.1 and $96.9 \%$, respectively. Further, the frequency of symptoms such as coughing $(>50 \%)$ and shortness of breath (30\%) is also similar, but pregnant women had less frequent headache, myalgia, fever, chills and diarrhea [3].

The difference between hospitalized women with COVID-19 and asymptomatic test-positive women is also important when considering the association between SARS-CoV-2 infection and perinatal mortality. The group with symptoms appears to be more susceptible to maternity and perinatal morbidity and severity [4].

It is important to note that the period in which the data of this study was collected there was a reduction in the number of cases detected in the city of Curitiba if compared with previous periods, as represented in Figure 1, provided by the Municipal Health Department [13]. This period of decline in the number of cases influences the prevalence found in the present study, although the daily number of active cases of COVID-19 during the study period varied between 3,000 and 4,800 cases.

Compared to other conventional laboratory tests, RT-PCR tests are usually valuable at the early stage of infection, when the viral load is low, and the antibodies have not yet been built. However, the evaluation of SARS-CoV-2 RT-PCR sensitivity has been performed in symptomatic individuals and the best performance presenting higher sensitivity has been obtained around the third day after symptoms onset [14]. Then, it is important to highlight that negative results cannot exclude SARS-CoV-2 infection. Although RT-PCR offers many benefits, it has some limitations: the low sensitivity, low stability and long turnaround time; besides that, several external factors may affect RT-PCR testing results accuracy: sampling operations, specimen source and the performance of detection kits, with high incidence of false negative diagnosis [14].

Serological tests could identify previous exposure to the pathogen, and unlike viral RNA, virus-specific antibodies are detected for several weeks to months after symptom onset. IgM antibodies to SARS-CoV-2 levels could be detectable in the blood just a few days after initial infection while the IgG becomes detectable three days from symptom onset or at least 7-10 days after infection, so these tests are not applicable for detection of acute infection. It is estimated that less than $40 \%$ of infected individuals are seropositive (IgM/IgA) in the first seven days, and there have been reports that those with mild cases of COVID-19 infection do not produce antibodies [14]. Thus, the interpretation of these tests and their correlation with the presence of disease still need to be better evaluated. 


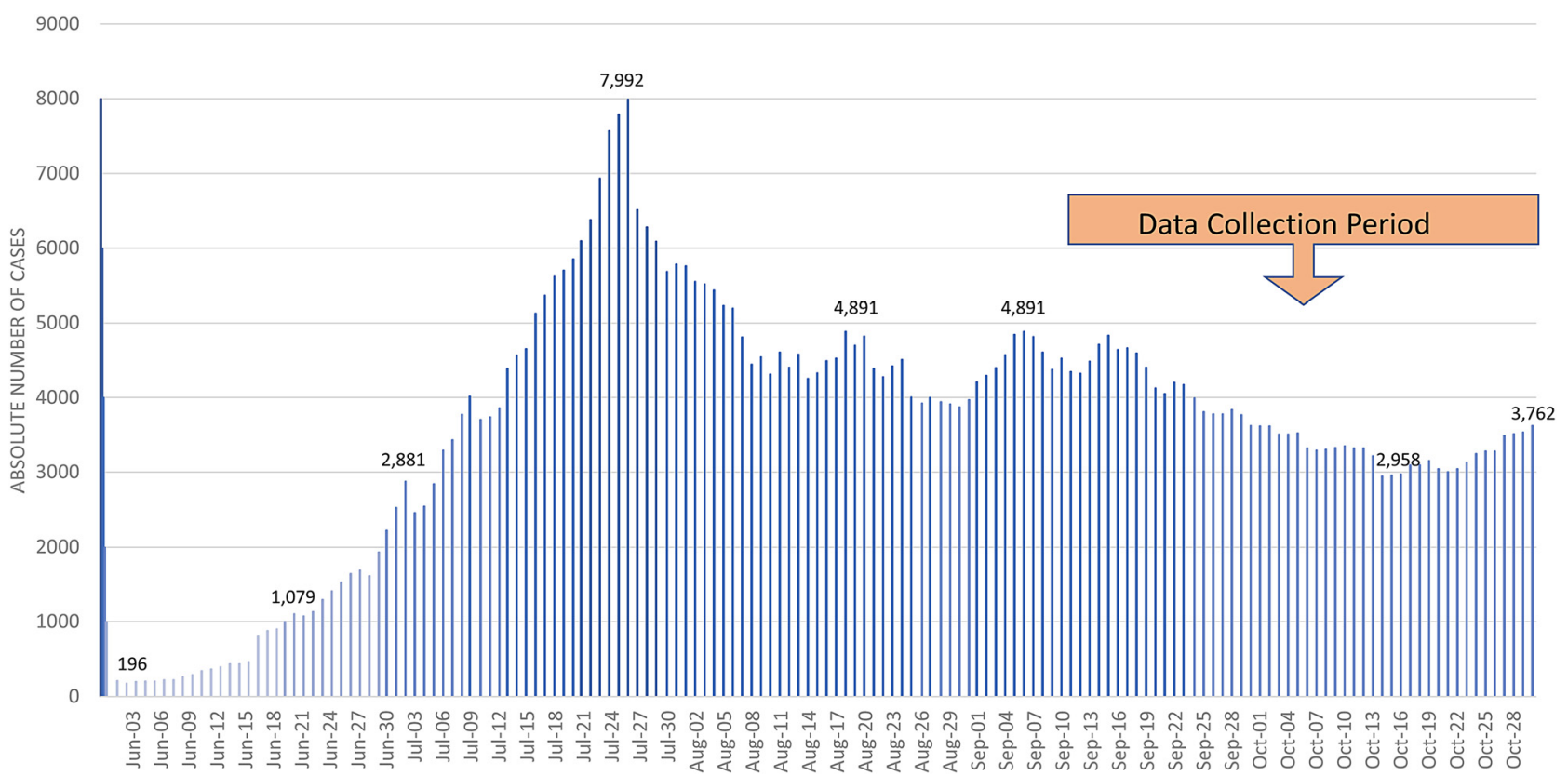

Figure 1: Daily number of confirmed active cases of COVID-19 in Curitiba - Brazil from June to October 2020 (based on data published by Health Curitiba Secretary. https://coronavirus.curitiba.pr.gov.br/painelcovid/).

Although COVID-19 is more contagious when an individual is symptomatic, transmission can also occur during the incubation period of the disease (asymptomatic or presymptomatic period), which has been estimated between 2 and 10 days $[15,16]$. The rate of viral transmission by asymptomatic and pre-symptomatic people can be also related to the speed and breadth of expansion of the pandemic by SARS-CoV-2. Therefore, it is essential that public and institutional policies are established to identify these individuals.

Early detection and quarantine of asymptomatic patients is one of the key points for preventing the transmission of SARS-CoV-2. However, a single ideal test for this screening is difficult to define, as the main tests have different characteristics and different detection times for infection. Therefore, a negative RT-PCR result should not be used as the sole criterion for the treatment or management decision of the patient, since it does not exclude the possibility of COVID-19 infection [17]. There is evidence that the spread of the virus can still occur at undetectable levels in the initial and final stages of SARS-CoV-2 infection, even with negative RT-PCR tests. The sensitivity of the RT-PCR test can be affected by the period of infection, since the early and late stages of the infection may not have sufficient viral load for detection, and may result in falsenegative results $[18,19]$. In such cases, serological tests, such as immunochromatographic tests (lateral flow chromatographic assay) or enzyme immunoenzymatic assays
(ELISA), may be important for confirming infection. Thus, test results should always be interpreted within a broader context [20].

This study presents some limitations, (a) the point-ofcare test for serological analysis has presented limited sensitivity and specificity performance, then positive results should be confirmed, (b) as well limitations of the reference test RT-PCR, (c) the number of research participants was limited due to a specific time frame of the study, which limits some epidemiological conclusions. Furthermore, the disease caused by SARS-CoV-2 is a global public health emergency, but the data related to the disease are being organized throughout the pandemic and there are still several controversies regarding its behavior during pregnancy and perinatal complications.

However, this study with RT-PCR and serologic detection for COVID-19, to our knowledge, is the first carried out in Brazil that assessed the prevalence of SARS-CoV-2 infection in asymptomatic pregnant women. Since the introduction of this virus in the country, Brazil is facing an unprecedented spread of this virus, there is a high community circulation due to, among other factors, a resistance of the population to adopt the recommended non-pharmacological measures. In public hospitals in the country, pregnant women who do not have respiratory symptoms share rooms with other patients and their newborns. Thus, conducting tracking and knowing the prevalence in these women is crucial to recommend isolation 
measures when applicable. Above all, an association of RT-PCR and serological testing increased the prevalence of asymptomatic pregnant women infected with SARs-CoV-2, which indicates that a single test may still be insufficient for the infection diagnosis and for the control of asymptomatic transmission.

Thus, this work can collaborate with new data about COVID-19 during pregnancy, in such a way that it can guide the planning of strategies for better management and measures to contain the spread of the virus, contributing to the reduction of infection complications in the maternalfetal binomial. Due to the high risk of this emerging infection in the health of pregnant women, fetuses and newborns, we suggest the universal screening of all pregnant women admitted to hospital through the combined method - RT-PCR and serological.

Acknowledgments: We first thank all the patients, who voluntarily agreed to participate in this study. We thank Mobius Life Science for donating the Biopur Viral Nucleic Acid Isolation Kit used for the RNA extraction from nasopharyngeal samples. We are grateful to the Department of Gynecology and Obstetrics, to the nursing time of prenatal care outclinic, to the entire team of the virology laboratory and to the Board of the Hospital de Clínicas of the Federal University of Paraná, who despite the crisis experienced did not measure efforts to help us to carry out this project successfully.

Research funding: This paper was financed in part by the Mobius Life Science donating the Biopur Viral Nucleic Acid Isolation Kit used for the RNA extraction from nasopharyngeal samples. The funding agencies had no role in the design of the study, data collection, data analysis, data interpretation, or writing of the manuscript. Author contributions: All authors were fundamental to the construction of the article, establishing the study design, data analysis and the preparation of the manuscript. There was a division between two groups: JAC, INF, JSL, CAF was responsible for the selection of patients, application of the Informed Consent Term and collection of material for research with supervision and orientation of NLECS and NSC. Another group was responsible for analyzing the samples in the virology laboratory: MBN, BMC and CTD. SMR was responsible for orientation of all steps for the study and final correction the manuscript. All authors are responsible for the preparation and correction of the manuscript.

Competing interests: The authors have no conflicts of interest.
Informed consent: Informed consent was obtained from all individuals included in this study.

Ethical approval: The Institutional Ethical Committee boarding reviewed and approved the study (CAAE: 35129820.6.0000.0096).

\section{References}

1. Wiersinga WJ, Rhodes A, Cheng AC, Peacock SJ, Prescott HC. Pathophysiology, transmission, diagnosis, and treatment of coronavirus disease 2019 (COVID-19) - a review. JAMA 2020;324: 782-93.

2. Nakamura MP, Amorim MMR, Pacagnella RC, Takemoto ML, Penso FC, Rezende-Filho J, et al. COVID-19 and maternal death in Brazil: an invisible tragedy. Rev Bras Ginecol Obstet 2020;42: 445-7.

3. Ellington S, Strid P, Tong VT, Woodworth K, Galang RR, Zambrano LD, et al. Characteristics of women of reproductive age with laboratory-confirmed SARS-CoV-2 infection by pregnancy status - United States, January 22-June 7, 2020. MMWR Morb Mortal Wkly 2020;69:769-75.

4. Di Mascio D, Buca D, Berghella V, Khalil A, Rizzo G, Odibo A, et al. Counseling in maternal-fetal medicine: SARS-CoV-2 infection in pregnancy. Ultrasound Obstet Gynecol 2021;57: 687-97.

5. Almeida SMD, Spalanzani RN, Nogueira MB, Spiri BS, Cavalli B, Rotta I, et al. Rapid serological tests for SARS-COV-2: diagnostic performance of four commercial assays. Med Princ Pract 2021. https://doi.org/10.1159/000516776 [Epub ahead of print].

6. Rizzo G, Mappa I, Maqina P, Bitsadze V, Khizroeva J, Makatsarya A, et al. Effect of SARS-CoV-2 infection during the second half of pregnancy on fetal growth and hemodynamics: a prospective study. Acta Obstet Gynecol Scand 2021;100:1034-9. [Epub ahead of print].

7. Yan J, Guo J, Fan C, Juan J, Yu X, Li J, et al. Coronavirus disease 2019 (COVID-19) in pregnant women: a report based on 116 cases. Am J Obstet Gynecol. 2020 [cited 2020]; 223: 111.e1-14.

8. Breslin N, Baptiste C, Gyamfi-Bannerman C, Miller R, Martinez R, Berstein K, et al. Coronavirus disease 2019 infection among asymptomatic and symptomatic pregnant women: two weeks of confirmed presentations to an affiliated pair of New York City hospitals. Am J Obstet Gynecol MFM 2020;2:100118.

9. Di Mascio D. Maternal and perinatal outcomes of pregnant women with SARS-CoV-2 infection. The WAPM (World Association of Perinatal Medicine) Working Group on COVID-19. Ultrasound Obstet Gynecol 2021;57:232-41.

10. Dória M, Peixinho C, Laranjo M, Varejão AM, Silva PT. COVID-19 during pregnancy: a case series from an universally tested population from the north of Portugal. Eur J Obstet Gynecol Reprod Biol 2020;250:261-2.

11. Bender WR, Hirshberg A, Coutifaris P, Acker AL, Srinivas SK. Universal testing for severe acute respiratory syndrome coronavirus 2 in 2 Philadelphia hospitals: carrier prevalence and symptom development over 2 weeks. Am J Obstet Gynecol MFM 2020;2:100226. 
12. Campbell KH, Tornatore JM, Lawrence KE, Illuzi JL, Sussman LS, Lipkind HS, et al. Prevalence of SARS-CoV-2 among patients admitted for childbirth in Southern Connecticut. JAMA 2020;323: 2520-2.

13. COVID-19 Curitiba Panel. Municipal health Secretary. COVID-19 monitoring [Municipal Health Secretary website]. Available from: https://mid.curitiba.pr.gov.br/conteudos/coronavirus/painelcuritiba-covid19.pdf [Accessed 15 Jan 2021].

14. Younes N, Al-Sadec DW, Al-Jighefee H, Younes S, Al-Jamal O, Daas $\mathrm{HI}$, et al. Challenges in laboratory diagnosis of the novel coronavirus SARS-CoV-2. Viruses 2020;12:582.

15. Sohrabi C, Alsafi Z, O'Neill N, Khan M, Kerwan A, Al-Jabir A, et al. World Health Organization declares global emergency: a review of the 2019 novel coronavirus (COVID-19). Int J Surg 2020;76: 71-6.

16. Çelebi G, Piskin N, Bekleviç AC, Altunai Y, Keles AS, Tüs MA, et al. Specific risk factors for SARS-CoV-2 transmission among health care workers in a university hospital. Am J Infect Contr 2020;48: 1225-30.

17. Tahamtan A, Ardebili A. Real-time RT-PCR in COVID-19 detection: issues affecting the results. Expert Rev Mol Diagn 2020;20: 453-4.

18. Bohn MK, Lippi G, Horvath A, Sethi S, Koch D, Ferrari M, et al. Molecular, serological, and biochemical diagnosis and monitoring of COVID-19: IFCC taskforce evaluation of the latest evidence. Clin Chem Lab Med 2020;58:1037-52.

19. Behrens GM, Cossmann N, Stankov MV, Witte T, Ernst D, Happle C, et al. Perceived versus proven SARS-CoV-2-specific immune responses in health-care professionals. Infection 2020;48: 631-4.

20. Lippi G, Simundic AM, Plebani M. Potential preanalytical and analytical vulnerabilities in the laboratory diagnosis of coronavirus diseases 2019 (COVID-19). Clin Chem Lab Med 2020; 58:1070-6. 